
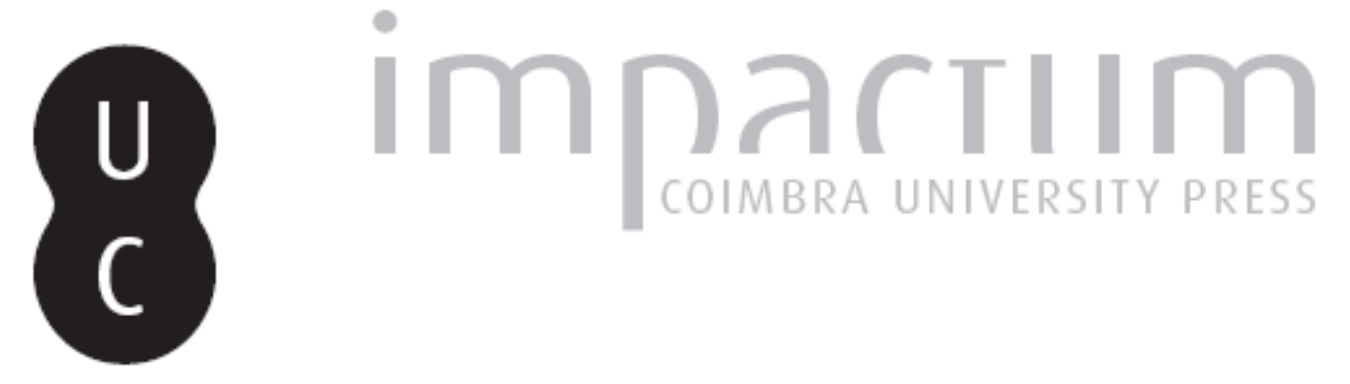

\title{
[Recensão a] Azevedo, Maria Teresa Nogueira Schiappa de - Platão: helenismo e diferença: raízes culturais e análise dos diálogos
}
Autor(es):
Oliveira, Francisco de

Publicado por: Annablume Clássica; Imprensa da Universidade de Coimbra

URL persistente:

URI:http://hdl.handle.net/10316.2/24314

DOI:

DOI:http://dx.doi.org/10.14195/1984-249X_9_14

Accessed : $\quad$ 26-Apr-2023 12:28:30

A navegação consulta e descarregamento dos títulos inseridos nas Bibliotecas Digitais UC Digitalis, UC Pombalina e UC Impactum, pressupõem a aceitação plena e sem reservas dos Termos e Condições de Uso destas Bibliotecas Digitais, disponíveis em https://digitalis.uc.pt/pt-pt/termos.

Conforme exposto nos referidos Termos e Condições de Uso, o descarregamento de títulos de acesso restrito requer uma licença válida de autorização devendo o utilizador aceder ao(s) documento(s) a partir de um endereço de IP da instituição detentora da supramencionada licença.

Ao utilizador é apenas permitido o descarregamento para uso pessoal, pelo que o emprego do(s) título(s) descarregado(s) para outro fim, designadamente comercial, carece de autorização do respetivo autor ou editor da obra.

Na medida em que todas as obras da UC Digitalis se encontram protegidas pelo Código do Direito de Autor e Direitos Conexos e demais legislação aplicável, toda a cópia, parcial ou total, deste documento, nos casos em que é legalmente admitida, deverá conter ou fazer-se acompanhar por este aviso.

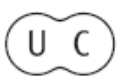




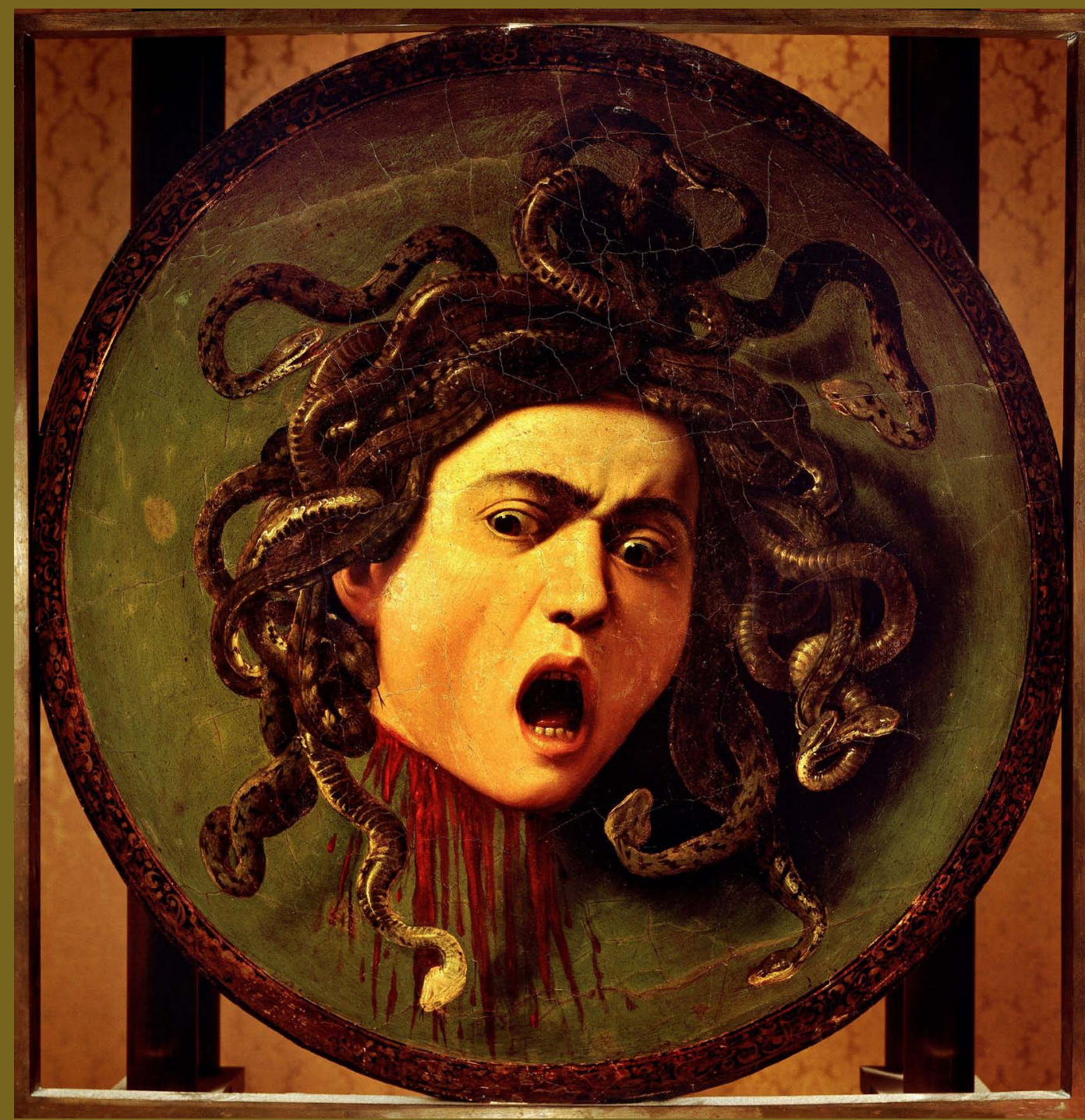

\section{R E V I S T A}
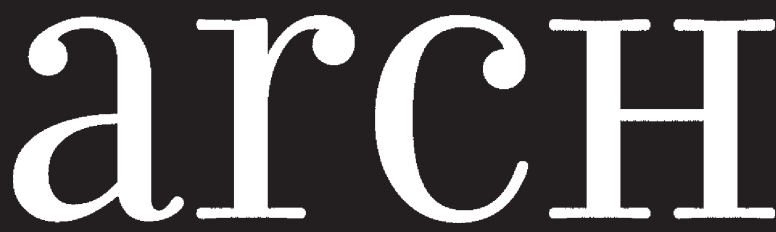
AS ORIGENS DO PENSAMENTO OCIDENTAL

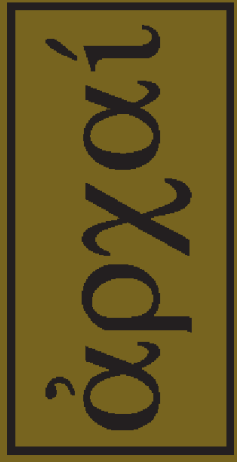

ARCHAI JOURNAL: ON THE ORIGINS OF WESTERN THOUGHT
arcHaI

arementam

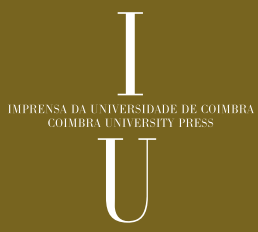

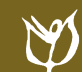

NNN 
Maria Teresa Nogueira Schiappa de Azevedo, Platão. Helenismo e diferença. Raízes culturais e análise dos diálogos. Coleção Archai. São Paulo, Annablume Clássica, 2012.

OLIVEIRA, F. (2012). “Maria Teresa Nogueira Schiappa de Azevedo, Platão. Helenismo e diferenças. Raízes culturais e análise dos diálogos. Coleção Archai. São Paulo, Annablume Clássica, 2012.". Archai n. 9, jul-dez 2012, pp. 137-140.
Universidade de Coimbra. Trabalho desenvolvido no Centro de Estudos Clássicos e Humanísticos, no âmbito do Projecto Quadrienal da UI\&DCECH/FCT POC 2010.

\section{Resenha de Francisco de Oliveira}

A obra "Platão. Helenismo e diferença. Raízes culturais e análise dos diálogos" aparece publicada sob patrocínio do grupo Archai, consagrado como Cátedra Unesco Archai, que se dedica às origens do pensamento ocidental. A editora é a AnnaBlumme Clássica, de São Paulo, de cujo conselho editorial faz parte o colega e amigo Gabriele Cornelli, que saúdo também como presidente da Sociedade Brasileira de Estudos Clássicos e enquanto cooperante com o Centro de Estudos Clássicos e Humanísticos da Universidade de Coimbra, em cujo âmbito foi elaborado o belo texto que tenho a honra e o prazer de apresentar.

E começo por me referir à sua autora, Maria Teresa Schiappa de Azevedo, que é bem conhecida pela inteligência, argúcia, capacidade crítica e escrita escorreita e elegante. Além disso, trata-se de uma investigadora que domina como poucos a obra de Platão, por um contacto de longos anos em estudos e traduções sempre de elevada qualidade, numa abrangência e aisance que logo são percetíveis na questão sempre difícil da cronologia da obra platónica, cuja discussão nas p.21-31 é um exemplo de análise especialmente conseguida e com grande capacidade crítica e espírito sintético, na linha de Cornford, embora divergindo dele quanto ao Fedro e ao Crátilo (cf. p.29). 
E não se trata de um simples rememorar desta velha questão, pois um dos mais profícuos resultados da investigação produzida é exatamente mostrar como, sobre um tema preciso, o pensamento platónico foi sofrendo evolução ao longo do tempo e graças às vivências do próprio filósofo. Essa evolução é rastreada tanto na evolução do pensamento como a nível da arte do diálogo, incluindo a caraterização das personagens e a sua origem, e a de Sócrates em especial (ver p.175 ss., início da Segunda Parte), bem como a escolha dos cenários dos diálogos. M. T. Schiappa de Azevedo assinalou ainda, de forma magistral, a maneira como essa evolução do pensamento e da arte de Platão correspondia, também, à evolução da Atenas coeva e do resto do mundo grego, que passam por alterações muito significativas, em especial na época em causa, entre Péricles e o período helenístico.

A edição agora em apreço faz juz a todas essas qualidades: bem informada, bem escrita, bem organizada. A obra estrutura-se em 3 partes, para além de uma Introdução:

\section{PRIMEIRA PARTE}

1. Pressupostos metodológicos (cronologia, Athenaioi, xenoi e barbaroi;

1. Cronologia

2. Athenaioi, Xenoi e Barbaroi

2.1. Estatuto genérico nos diálogos platónicos 31

2.2. 0 testemunho do Crátilo

2. Sócrates em Platão

1. Sócrats e Atenas

2. Sócrates e xenoi

3. Incidências orientais e recriação platónica

1. Música grega e incidências orientais

2. Divindades orientais e recriação platónica

2.1. As duas Afrodites

2.2. Adónis

105

2.3. 0 dionisismo

2.4. o xamanismo

SEGUNDA PARTE. Diálogos da primeira e da segunda fases
1. Atenas no contexto helénico

1. A cidade 175

2. A cidade e os mitos das origens 178

2.1. 0 Eutidemo e o mito de Íon 178

2.2. 0 Menéxeno e o mito da autoctonia 185

3. Menção genérica de outros Estados gregos 190

4. Lacedemónios 194

2. Atenas e a Antinomia Grego / Bárbaro 213

1. Contextualização 213

2. 0 testemunho dos diálogos 217

3. 0 Grande-Rei 224

4. Nomos / Physis na antinomia Grego / Bárbaro

TERCEIRA PARTE. Diálogos da terceira fase (últimos diálogos) 249

1. Atenas no contexto helénico 251

1. Atenienses e Xenoi 251

2. A Academia e a experiência siciliana 260

3. Uma nova vivência de xenia 283

2. Atenas e Bárbaros 291

1. Linhas de evolução 291

2. Egípcios 307

2.1. Contextualização 307

2.2. 0 Egipto de Platão 311

3. Persas

3.1. Contextualização 327

3.2. A Pérsia de Platão 331

4. Vias de superação da antinomia Grego /

Bárbaro

Em relação a esta estrutura, acrescem conclusões (p.347) bem apropriadas e muito lógicas e fundamentadas; bibliografia exaustiva e criteriosa; um bom índice de autores antigos e fontes.

Diria somente que me pareceria interessante acrescentar um índice temático, pois temas e conceitos interessantes não faltam nas páginas que preenchem o esquema apresentado.

É o que logo se vê nas páginas introdutórias. Num verdadeiro sumário do estado da questão, a própria autora afirma, na p.12: são “escassos os estudos que tratem a questão incontornável da relação grego/ bárbaro através do texto platónico", prejudicada, para alguns críticos, “pelo peso do 
passo 470c-471b da República, onde a cruzada pan-helénica da retórica do tempo se traduz na palavra de ordem "contra os Bárbaros". Mas é a excepção e não a regra, como espero deixar demonstrado na análise que se segue".

São também explanados alguns pressupostos metodológicos, que enuncio novamente através das palavras da própria autora (p.15-16):

- "a imprescindibilidade de distinção entre estrangeiro grego (xenos) e estrangeiro bárbaro (barbaros), sem a qual será difícil evitar algumas ambiguidades interpretativas - como sucede no estudo, em vários aspectos aliciante, de H. Joly;

- a importância da língua na perspectivação da dicotomia grego/ bárbaro (e parcialmente, da sua superação), de acordo com as reflexões linguísticas e etnográficas que passam do séc. $V$ a.C. às décadas iniciais do século seguinte, concentrando-se no Crátilo;

- a projecção da figura de Sócrates num conceito de cidadania que congloba valores atenocêntricos específicos, sobretudo presentes na primeira fase dos diálogos (mas nunca de todo abandonados);

- a viragem essencial que eventos decisivos da vida de Platão, nomeadamente a primeira viagem à Sicília e a fundação da Academia, consignam na abertura dos diálogos do último período ao mundo dos xenoi e dos barbaroi".

Esta súmula permite facilmente entrever a riqueza de conteúdo de um estudo que, logo ao escolher a temática proposta, vai tratar um vasto acervo de questões de grande relevância em termos científicos e de atualidade, e alguns até espinhosos, como a interpretação do papiro de Derveni.

Respigo algumas ideias da leitura que fiz. Schiappa de Azevedo sabe contextualizar muito bem as problemáticas discutidas, mostrando como o fenómeno de aculturação se relaciona com permutas e veículos diversos, incluindo a diplomacia e a guerra, o que se torna evidente nos intercâmbios com a Pérsia após as invasões do continente grego. Aqui, o bárbaro inimigo já tinha uma história de relacionamento com a Hélade desde a época minóica e micénica, e em particular desde o período arcaico, quando a aristocracia usava marcas de vestuário persa como sinal de elitismo, fenómeno a que Miller chama perserie (p.299); o inimigo bárbaro, dizia, verá a sua imagem liberta dos estereótipos tradicionais que baseavam a felicidade do Grande Rei no ouro, ideia desprezada no Teeteto, 175c (p.275; cf. Lísis, 209d, Ménon, 78d ou a embaixada persa nos Acarnenses de Aristófanes); sob a influência de Xenofonte, a Pérsia passa mesmo a fornecer paradigmas de comportamento à sociedade grega (p.336). Mais do que isso, é bem posto em relevo como a evolução cultural está fatalmente ligada a circunstancialismos históricos, como quando o imaginário grego substitui o bárbaro persa pelo bárbaro cartaginês ou osco, agora os verdadeiros inimigos de um pan-helenismo já alargado, em finais do séc. V, aos colonos gregos da Magna Grécia e da Sicília.

0 exempo da Pérsia e do Grande Rei é apenas uma faceta da apropriação das sabedorias bárbaras praticada pelos gregos, apropriação que, naturalmente supõe ou cria as condições para o reconhecimeno, nos bárbaros, de um Outro que tem mérito e que pode, até, ser superior aos gregos em domínios específicos, da religião à organização política, a ponto de a imagem da Pérsia ideal — a de Ciro - , lembrar Atenas nos seus melhores tempos (p.333; cf. Carta VII, 332a-b, que classifica Dionísio I de Siracusa como "sete vezes menos sábio do que Dario", p.336). Isto para não falar noutros sinais da influência assíria, caldaica e mesopotâmica, com que poderíamos relacionar os mitos da República e do Fedro, ou a filosofia dualista do Bem e do Mal, do Alcibíades I.

É esse também o caso do Egipto, cuja fonte de conhecimento primacial, à época, é o livro II de Heródoto, um Egipto exaltado por domínios artísticos, como a música e a dança, e científicos, como a farmacologia, a escrita, o ensino da matemática (veja.-se o mito de Theu, no Fedro e Leis 819bd); a aura de simpatia de que goza em Atenas assenta, além do mais, em alegadas relações entre Atenas e Saís - que, segundo o Timeu, 21e e 23-24, teriam sido fundadas pela mesma divindade (Neith na língua egípcia, Atena em grego) - e que beneficiariam de um intercâmbio regular, estabelecido após a fundação do porto de Náucratis e da colónia de Cirene, 
bem como do casamento do faraó Âmasis com uma grega. Os atenienses e Platão admiram no Egipto a sabedoria milenar e a estabilidade política de um regime baseado numa hierarquia social que terá servido de inspiração à República e às Leis.

A brevidade implícita nesta apresentação permite-me ainda relevar o modo como a cidade de Atenas é apresentada, e com bom fundamento na obra platónica, como cidade que, apesar do mito da autoctonia ou até graças a ele - e fazendo juz às referidas ligações preferenciais ou até originárias com a Iónia e com Saís - , se vai sabendo abrir à diversidade e à tolerância, primeiro na perspetivação de um ideal pan-helénico, depois a estrangeiros bárbaros, firmando-se no culto de Zeus Xenios (Leis, 953de). Acompanhando este percurso, a Academia funciona, a seu tempo, como instituição aberta a xenoi de toda as cidades gregas e mesmo a estrangeiros - e quadra bem ter sido doado por Anicéris de Cirene o terreno onde se fundou a Academia. Como escreve a autora, p.326: "os sistemas legislativos platónicos mantêm no conjunto o respeito pela diversidade, que os diferentes povos e Estados gregos foram consciencializando na sua evolução comum".

Em suma, recomendo esta leitura, tanto pelo valor científico como por ser uma imagem expressiva da verdadeira paideia grega, base da tolerância europeia da alteridade. E Schiappa de Azevedo demonstrou cabalmente o enorme contributo de Platão para essa maravilha: "Ao longo do séc. V a. C., o conhecimento e a aceitação mútua de padrões civilizacionais diversos foram ganhando 'simpatizantes dos Gregos' (phillelenes) entre os Bárbaros e 'simpatizantes dos Bárbaros' (philobarbaroi) entre os Gregos (p.343); ou ainda, a propósito das Leis e do uso polissémico do termo xenos: “o intercâmbio deliberado da condição de xenoi, que os três interlocutores partilham entre si nas fórmulas de tratamento, anula idealmente a dicotomia entre polites e xenos, presente de forma mais ou menos perceptível nos diálogos anteriores" (p.285-286). 